\title{
LOS VÍNCULOS COMERCIALES Y DE INVERSIÓN SUR-SUR: REFLEXIONES SOBRE LA RELACIÓN BRASIL-ANGOLA
}

\author{
Michelle Ratton Sanchez Badin \\ FABIO MOROSINI
}

\section{INTRODUCCIÓN}

En los últimos años, se ha observado un cambio de las características de la geografía mundial en cuanto a los flujos comerciales y de inversión. * En 2013, los flujos de inversión extranjera directa (IED), para las economías en desarrollo, ${ }^{1}$ representaron 54\% (778 000 millones de dólares) del total global. Con respecto de la exportación de IED, a pesar de que los países del Sur tengan registros resilientes, que alcanzan 454000 millones de dólares, su participación ha ido en aumento, mientras que la de los del Norte está estanca-

* Esta investigación ha recibido el apoyo de CAPES/CNPq (MCTI/CNPq/MEC/ CAPES n. 43/2013) y de la Fundação de Amparo a Pesquisa do Estado de São Paulo (FAPESP) (2014/25776). Los autores agradecen el apoyo de la FGv Direito sp y de la Facultad de Derecho de la Universidad Federal de Rio Grande do Sul (UFRGS), así como a los miembros de los grupos de investigación de la misma institución y de la FGV vinculados al proyecto de investigación "Evidencias empíricas en derecho internacional económico: el caso de Angola”. Agradecemos también a los evaluadores anónimos de este periodo por las sugerencias para complementar y conducir a nuevas reflexiones. Los errores son responsabilidad exclusiva de los autores.

${ }^{1}$ El Banco Mundial denomina como países en desarrollo a aquellos de medios y bajos ingresos (low and middle income), a partir del cálculo de la franja de renta con base en el rendimiento nacional bruto per capita en dólares americanos. Véase: https:/ / datahelpdesk.worldbank.org/knowledgebase/articles/378834-how-doesthe-world-bank-classify-countries 
da. ${ }^{2}$ El comercio global acompaña esa tendencia: la participación de las economías en desarrollo pasó de 34 a 47\% entre 1980 y 2011. Según las estadísticas de la Organización Mundial de Comercio, la participación del comercio Sur-Sur en el comercio mundial pasó de $8 \%$ en 1990 a $24 \%$ en $2011 .^{3}$

En este contexto de proyección de las relaciones contemporáneas Sur-Sur de comercio e inversión, constatamos la falta de bibliografía especializada sobre las modalidades de los acuerdos jurídicos entre esos países. Sospechamos que una variedad de herramientas jurídicas se puso en práctica para regular los diferentes acuerdos, a partir de las especificidades de las economías involucradas. A la luz del ejemplo de Brasil, señalado como uno de los líderes emergentes en la nueva economía política, se observa que el país firmó pocos acuerdos comerciales regionales (ACR) y que nunca ratificó un tratado bilateral de inversión (тві). ${ }^{4}$ Aunque Brasil no aparezca en los modelos de acuerdo, para regular sus relaciones comerciales y de inversión, el flujo de comercio, a partir de y para el país, aumentó en las últimas décadas, al igual que los flujos de entrada y salida de inversiones.

Para tratar esta cuestión, tomamos el ejemplo de las relaciones económicas entre Agola y Brasil. Los flujos comerciales y de inversión entre Angola y Brasil han sido particularmente dinámicos para las economías de ambos países en los últimos años. Como una de las mayores economías de África, ${ }^{5}$ no debe sorprender el

${ }^{2}$ UNCTAD, World Investment Report 2014, Ginebra, UNCTAD, 2014, p. 36.

${ }^{3}$ oMc, 2013, p. 6.

${ }^{4}$ Entre marzo y octubre de 2015, Brasil firmó acuerdos de cooperación y facilitación de inversiones con seis países del Sur global: Mozambique, Angola, México, Malaui, Colombia y Chile. Estos acuerdos esperan ratificación del Congreso Nacional. Los textos de los acuerdos están disponibles en: http:/ dai-mre.serpro. gov.br/atos-internacionais/bilaterais/2015/

${ }^{5}$ El PIB de Angola fue el sexto mayor del continente africano, con un total de 130000 millones de dólares. Durante el periodo de 2005 a 2013, era el único país, además de Etiopía, en tener un crecimiento anual del PIB de dos dígitos. Para mayores datos sobre el Panorama Económico Africano, puede consultarse http:/ / www.africaneconomicoutlook.org/ Según algunos informes internacionales, África se considera el próximo mercado por conquistar, por sus recursos naturales y su promisorio mercado consumidor. 
hecho de que Angola sea el país con el que Brasil ha aumentado más sus flujos de comercio e inversión en los últimos quince años. Si en 2002 los flujos de inversión brasileña para Angola se aproximaban a 18 millones de dólares, en 2012 ya alcanzaban mil millones de dólares. ${ }^{6}$ Los flujos comerciales registraron un crecimiento de 11 millones de dólares en las importaciones brasileñas oriundas de Angola en 2002, con que llegaron a 726 millones de dólares en 2013 y de 199 millones de dólares en las exportaciones brasileñas para Angola en 2002 para 1271 millones de dólares en $2013 .{ }^{7}$ Por tanto, lo que justifica la elección de Angola no es el volumen del flujo económico ni el margen que ocupa en el flujo total de comercio e inversión de Brasil (alrededor de $0.4 \%$ ), sino su aumento de hasta cuatro veces más en los últimos cuatro años.

En el presente artículo, procuramos identificar cuáles son los acuerdos legales que promueven el aumento del flujo de inversiones y comercio del país en este marco general de aproximaciones Sur-Sur. La hipótesis de este trabajo es que, si hubo este aumento en las relaciones económicas entre Brasil y Angola, hay acuerdos legales específicos que sustentan esos movimientos. A partir de esta premisa de investigación, nos proponemos explorar cuestionamientos específicos. A saber: ¿emplea Brasil estándares regulatorios en los modelos de acuerdos regionales de comercio y tratados bilaterales de inversión o recurre a otro tipo de acuerdos jurídicos?; ¿qué tipo de instituciones movilizan éstos en cada país?; ¿cómo sucede la interacción entre los actores públicos y privados? Revisaremos las características de las políticas de apoyo a este movimiento y las reglas destinadas a promover el aumento de relaciones económicas y cómo pueden complicar algunos conceptos que han orientado la producción académica de las relaciones económicas internacionales en las áreas de la ciencia política, el derecho y la economía.

${ }^{6}$ Banco Central do Brasil, "Estatísticas econômicas de capitais brasileiros no exterior", 2014, en http://www4.bcb.gov.br/rex/cbe/port/cbe.asp

${ }^{7}$ Datos obtenidos del Ministério do Desenvolvimento, Indústria e Comércio do Brasil, en http://www.mdic.gov.br/ En este periodo, Brasil importó gas natural licuado y, sobre todo, petróleo bruto, y exportó a Angola, en orden decreciente, carne, azúcar y maquinaria. Datos recogidos en http://www.trademap.org/Bilateral.aspx?nvpm=1|076||024||TOTAL|||2|1|1|1|1||1|1| 
Para desarrollar el análisis propuesto, este artículo se ha organizado en cuatro secciones: la descripción histórica de los acuerdos regulatorios que controlaron las relaciones de comercio e inversión entre Angola y Brasil, a partir de las circunstancias políticas y económicas de cada periodo; los orígenes de las alternativas económicas y regulatorias; la influencia de las políticas liberales en los proyectos de cooperación; y la reanudación de la cooperación Sur-Sur por nuevas herramientas y nuevos actores. Esbozamos algunas consideraciones, en fin, sobre las particularidades con que Angola y Brasil superan las limitaciones económicas internacionales para sus relaciones bilaterales. Agregamos además algunas apreciaciones sobre las estructuras sociopolíticas que han sustentado esas relaciones y que han contribuido a las particularidades jurídicas de sus acuerdos. Nuestro objetivo es contribuir con la expansión de categorías para la comprensión de las relaciones económicas que se establecen en el Sur global.

\section{BReves ANTECEDENTES históricos de LAS RELACiONES ENTRE Brasil y ANgola: ¿RUPTURA O CONTINUIDAD?}

Brasil fue el primer país en reconocer la independencia de Angola en 1975. Con todo, ese movimiento se tuvo por disidente en la política exterior brasileña durante la Guerra Fría ${ }^{8}$. El presidente brasileño era entonces Ernesto Geisel (1974-1979), a quien se conoce por haber promovido una política exterior independiente,

${ }^{8}$ Cuando Brasil reconoció a Angola como país independiente, el partido en el poder (Movimento Popular Pela Libertação de Angola, MPLA), que tenía una relación próxima con el bloque soviético, fue considerado como un grupo marxista. Brasil, en cambio, estaba asociado a otro bloque (el americano) y formaba parte del patio trasero de la política exterior estadounidense, como toda América Latina (Saraiva, "Um momento especial nas relações Brasil-Angola: do reconhecimento da independência aos desdobramos atuais", en Saraiva y Pantoja, Angola e Brasil nas rotas do Atlântico Sul, São Paulo, Bertrand Brasil, 1999, pp. 225 ss.). El apoyo de Brasil a Angola favorecía, mientras tanto, la coordinación de los países no alineados, que incorporaba a los nuevos países independientes de África y Asia, además de los de América Latina (Penha, Relações Brasil-África e geopolítica do Atlântico Sul, Salvador, Edufba, 2011, pp. 162 ss.) 
el fortalecimiento de empresas estatales y una nueva política para el sector energético. De ésta se destaca la construcción de la hidroeléctrica Itaipu Binacional, la creación del Programa Nacional del Alcohol de Brasil (conocido como Pró-Álcool, en portugués), los acuerdos nucleares con Alemania y, sobre todo, la búsqueda de otros proveedores de petróleo. ${ }^{9}$ Angola se convirtió, en estas circunstancias, en una alternativa para Brasil en el punto culminante de la crisis mundial de petróleo.

Aunque la política pragmática para los nuevos países independientes en África haya tenido un efecto comercial positivo -por haber establecido un mercado para el excedente de las manufacturas brasileñas y garantizado la provisión de petróleo-, ${ }^{10}$ académicos y funcionarios brasileños concuerdan en que esta política no se reducía a eso. ${ }^{11} \mathrm{La}$ importancia del movimiento de aproximación a los países africanos hace poco independientes, en las décadas de 1960 y 1970, se ha atribuido también a la necesidad de llenar el "vacío político" entre los continentes y de ocupar el espacio del Atlántico sur. ${ }^{12} \mathrm{Al}$ igual que en el proceso de independencia

${ }^{9}$ Antes de ser presidente del país, Geisel ocupó la presidencia de Petrobras, paraestatal petrolera de Brasil (1969-1974), cargo en que tuvo la oportunidad de acompañar el éxito de prospección de petróleo en Angola, según su propio testimonio en D’Araujo y Castro (orgs.), "Política externa e pragmatismo responsável", entrevista con el presidente Geisel, Río de Janeiro, CPDOC, FGV, 1994.

${ }^{10}$ En la actualidad, Brasil se considera autosuficiente en la oferta de petróleo, pero, de todas sus importaciones entre 1975 y 1979, las de petróleo representaron el $70 \%$ (Penha, op. cit., p. 171). Por ello, Antônio Azeredo Silveira, ministro encargado de las relaciones exteriores en aquel momento, calificó de "pragmatismo responsable” la política de aproximación con Angola y otros países. Sobre las características de esta política, véanse los testimonios oficiales en Silveira, entrevista de 1978, pp. 46-47, y Guerreiro, "Interview 1985”, 2010, p. 221, así como los análisis académicos en Cervo y Bueno, História da política exterior do Brasil, Brasilia, IBRI/ UnB, 2002, pp. 420-424, y Penha, op. cit., p. 168.

${ }^{11}$ En ese sentido, véase Cervo y Bueno, op. cit., pp. 420-424, y Penha, op. cit., p. 164.

12 "Vacío político" es una expresión que usan algunos especialistas brasileños para referirse a la falta de política estructurada en un país, como Brasil, cuyos movimientos en el continente africano antes de 1960 carecían de una política estructurada. Por tanto, había un vacío en la concepción de una región del Atlántico Sur que fue explorada por una política externa más independiente, proyectada a 
de Angola, Brasil evocó siempre, en su relación con ese país, semejanzas históricas y culturales, condiciones geográficas, así como las ventajas políticas y económicas de una alianza entre los países del sur. ${ }^{13}$ El discurso oficial regresa siempre, en consecuencia, al momento afortunado de 1975 y a sus narrativas, además de resonar también en los discursos angoleños. ${ }^{14}$

La política exterior brasileña para con África, Angola incluida, se ha descrito como "cíclica" en la academia brasileña. ${ }^{15}$ Con todo, la narrativa diplomática intenta siempre dar la impresión de la continuidad de la relación Angola-Brasil. Como ejemplo, tras el declive de la política exterior brasileña en África durante la década de 1990, en 2003 el presidente Lula, en su primer año en el cargo, visitó Luanda y declaró en la reunión ministerial bilateral: "Asociados de larga data, Angola y Brasil se preparan para consolidar y ahondar su cooperación [...]. Nuestras relaciones se inscriben en un contexto de afinidades espontáneas y solidaridad recíproca. Estas circunstancias explican por qué Angola es desde su independencia una prioridad de nuestra diplomacia". ${ }^{16}$

Del discurso a los compromisos legales, observamos que el enfoque pragmático incorporó la idea de cooperación como elemento

partir de la década de 1960 e implementada durante la de 1970. Sobre el tema, véanse Silveira, entrevista citada; Cervo y Bueno, op. cit., pp. 397-426; y Saraiva, "Um momento especial nas relações Brasil-Angola...".

${ }^{13}$ Véase la deposición de Geisel en D’Araujo y Castro, entrevista citada. Para mayor información sobre el reconocimiento de la independencia de Angola por parte de Brasil, véanse los testimonios de Silveira (entrevista citada, pp. 3-5), por entonces ministro de Relaciones Exteriores en cargo, y de Guerreiro (entrevista citada, pp. 209-219), ministro de Relaciones Exteriores de 1979 a 1985.

${ }^{14}$ Véase Ana Saggioro Garcia, Karina Kato y Camila Fontes, "A história contada pela caça ou pelo caçador? Perspectivas sobre o Brasil em Angola e Moçambique”, Instituto Pacs, 8 de marzo de 2013, p. 19.

15 José Sombra Saraiva ("Política exterior do Governo Lula: o desafio africano”, Revista Brasileira de Política Internacional, vol. 45, núm. 2, 2002) describe ese movimiento compuesto por "oportunidades, crisis y más vueltas".

16 MRE, Repertório de política externa: posições do Brasil, Brasilia, FUNAG, 2007, pp. 166-167. 
central en la relación entre Angola y Brasil. ${ }^{17}$ La cooperación SurSur, de forma general, se ha propuesto como una alternativa a la Asistencia Oficial para el Desarrollo (AOD), que se considera del Norte hacia el Sur. ${ }^{18}$ En esencia, esta cooperación se funda en la no condicionalidad de la asistencia, pero, a la vez, incorpora los conceptos de expansión de la inversión y de comercio entre los países del Sur. ${ }^{19}$

Brasil firmó alrededor de setenta acuerdos y protocolos con Angola. El primero, y uno de los más importantes, se firmó el 11 de junio de 1980; se titula “Acuerdo de Cooperación Técnica, Económica y Científica”. Es un acuerdo-paraguas que puede modificarse y matizarse con acuerdos posteriores, así como con contratos entre las partes (artículo III). Éste sirvió de base para quince acuerdos

17 Algunos de los principios consolidados por la onU sobre la cooperación Sur-Sur (UN SSC / 17/3, de 12 de abril de 2012) ya estaban en el preámbulo del Acuerdo de Cooperación Técnica Económica y Científica, firmado en 1980 por Angola y Brasil: "Considerando el interés común de acelerar el desarrollo económico, técnico y científico de los países en la base de los principios de igualdad de derechos, de respeto mutuo de la soberanía y de la injerencia en los asuntos internos de cada Estado".

${ }^{18}$ La Asamblea general de las Naciones Unidas reafirmó recientemente tales particularidades y su importancia: "3. Flows of development assistance from the North and the South are significantly different, however, and South-South cooperation is much wider than financial and technical support; it is a broad consultative and collaborative process engaging all developing countries, aimed at improving their collective economic, social and political capacity and welfare" (U.N. General Assembly, 67th session, "The state of South-South cooperation Report of the Secretary-General", A/67/208). Véase también "Nairobi outcome document of the High-level United Nations Conference on South-South Cooperation", A/64/222, 20 de febrero de 2010. Para una introducción a la agenda Brasil-África en el contexto de cooperación Sur-Sur, véase IPEA y Banco Mundial, Ponte sobre o Atlântico - Brasil e África Subsaariana: parceria Sul-Sul para o crescimento, Brasilia, 2011.

${ }^{19}$ Para una visión crítica de los beneficios de la cooperación Sur-Sur en comparación con la asistencia Norte-Sur, véase Fahimul Quadir, "Rising Donors and the New Narratives of South-South Cooperation: What Prospects for Changing the Landscape of Development Assistance Programmes?”, Third World Quarterly, vol. 34, núm. 2, 2013, p. 333. Según Quadir, la retórica de ayuda sin condiciones no presenta suficientes evidencias empíricas en las donaciones de los países del Sur considerados, a saber: Brasil, la India, China y Sudáfrica. 
complementarios y tres protocolos firmados desde la década de 1980 hasta el día de hoy entre Brasil y Angola. ${ }^{20}$ El acuerdo de 1980 también estableció una Comisión Mixta para administrar las relaciones bilaterales (artículo xI), la cual ha sido responsable de avanzar en temas de cooperación y otros asuntos de interés mutuo. La última reunión de la Comisión Mixta de la que tenemos noticia se realizó en 2005. Esa comisión aún existe, pero, desde 2010, según la Declaración Conjunta para una Asociación Estratégica, firmada por los presidentes de ambos países, se creó un segundo espacio institucional, la Comisión Permanente Bilateral. La nueva Comisión se encarga de supervisar la implementación del Plano Estratégico (sesión E.27 de la declaración Conjunta), cuya primera reunión se sostuvo los días 29-30 de octubre de 2012. ${ }^{21}$

Con estos acuerdos y protocolos se estrechan las relaciones económicas entre Brasil y Angola, pero no retiran las limitaciones presentes en transacciones comerciales entre ambas economías en desarrollo. Eso exige tanto de Brasil como de Angola ser creativos para superar los obstáculos que hay entre ellos.

${ }^{20}$ El Ministerio de Relaciones Exteriores brasileño clasifica como "acuerdos de ajuste complementario" "el acto que da ejecución a otro, anterior, debidamente concluido y en vigor, o que detalla áreas de entendimiento específicas abarcadas por aquel acto". Los protocolos, por otro lado, designan "acuerdos menos formales que los tratados, o acuerdos complementarios o interpretativos de tratados o convenciones anteriores. Se utiliza aún para designar el acta final de una conferencia internacional. Ha sido usado, en la práctica diplomática brasileña, muchas veces bajo la forma de «protocolo de intenciones» para señalar un inicio de compromiso". Para definiciones oficiales y otras clasificaciones de acuerdos internacionales, véase http://dai-mre.serpro.gov.br/apresentacao/tipos-de-atosinternacionais/ Un análisis más detallado de los acuerdos firmados por Brasil y Angola y otros países africanos, puede verse en Wilson Mendonça Júnior, Política externa e cooperação técnica: as relações do Brasil com a África durante os anos FHC e Lula da Silva, Brasilia, D’Plácido, 2013, pp. 117-141.

${ }^{21}$ Para más detalles sobre la asociación estratégica, véase http://www.itamaraty.gov.br/sala-de-imprensa/notas-a-imprensa/visita-ao-brasil-do-presidente-darepublica-de-angola-jose-eduardo-dos-santos-2013-23-de-junho-de-2010-2013-declaracao-conjunta Sobre las reuniones bilaterales, http://www.itamaraty.gov.br/ index.php?option=com_content\&view=article\&id $=4817 \&$ Itemid $=478 \& c o d$ pais=AGO\&tipo=ficha_pais\&lang=pt-br 


\section{Pragmatismo regulatorio como resultado de las}

LIMITACIONES ECONÓMICAS DE LAS RELACIONES BRASIL-ANGOLA: COUNTERTRADE, CONCESIÓN DE CRÉDITO Y PRÉSTAMOS CON GARANTÍA

Sostenemos aquí que la relación entre Angola y Brasil considera con claridad las limitaciones económicas para sus iniciativas políticas y asociaciones bilaterales. Por tanto, buscamos identificar cómo los dos países han creado alternativas jurídicas que posibilitan la intensificación de sus relaciones económicas, conforme a las particularidades políticas y económicas, nacionales e internacionales, de cada periodo histórico.

El Acuerdo para la Cooperación Económica, Científica y Técnica se firmó en 1980, cuando el modelo de desarrollo de la mayoría de los países de América Latina -incluido Brasil- y de África colapsaba. La crisis de crédito y las altas tasas de interés eran problemas comunes, si bien habían afectado a las economías latinoamericanas y africanas de maneras distintas. ${ }^{22}$ En los años setenta las relaciones económicas entre Angola y Brasil se habían estructurado según el flujo comercial: Brasil exportaba productos manufacturados y semimanufacturados y Angola exportaba petróleo y derivados. En 1979, Brasil invirtió por primera vez de manera directa en Angola, en especial en el sector petrolero del país, por intermediación de la paraestatal Petrobras, cuya participación combinó el acceso a fuentes de petróleo con la oportunidad de exportar productos y tecnologías brasileños. ${ }^{23}$

${ }^{22}$ Gharam Ghai y Cynthia Hewitt Alcantara, "The Crisis of the 1980's in SubSaharan Africa, Latin America and the Caribean: Economic Impact”, Social Change and Political Implications: Development and Change, vol. 21, 1990, pp. 401-403.

${ }^{23}$ Petrobras inició su proceso de internacionalización en 1972 por medio de la creación de la subsidiaria Beaspetro para inversiones fuera de Brasil. Según Paiva (Proposta de variáveis críticas para o modelo preliminar de apoio à decisão de aquisição de refinarias em novos mercados, tesis, Río de Janeiro, Pontifícia Universidade Católica do Rio de Janeiro, 2009, p. 17), en aquel momento la estrategia de Petrobras fue invertir en el exterior con el propósito de obtener mercado para los productos y la tecnología desarrollada de Brasil. Esto era posible porque a mediados de los años setenta Petrobras consiguió ponerse a la par de la tecnología internacional que había en el sector. La internacionalización fue también una de las estrategias para superar los límites de la crisis internacional del petróleo. 
A partir de 1984, a causa de la crisis financiera internacional, ante la escasez de moneda y el exceso de bienes y servicios, Brasil reconoció la posibilidad de implementar el countertrade (modalidad de intercambio comercial) en sus relaciones con los países africanos, incluida Angola. ${ }^{24}$ Esta solución ingeniosa fue útil para los dos países en un momento en el que había inestabilidad en sus modelos de desarrollo y enfrentaban la falta de liquidez internacional. ${ }^{25}$

Con todo, la crisis financiera y de deuda no era la única dificultad que enfrentaba Angola en los años ochenta. Luego de la muerte de su primer presidente, Agostinho Neto, en 1979, y de la designación de José Eduardo dos Santos para el cargo, el principal movimiento político de oposición, Unión Nacional para la Independencia Total de Angola (UNITA), hizo esfuerzos y comenzó una guerra civil que perduró hasta 2002. ${ }^{26}$ Por este conflicto civil, el Acuerdo de 1980 fue enmendado, en 1983, por un Ajuste Complementario sobre Asuntos de Comercio y un Protocolo Adicional sobre Cooperación en el Campo de las Comunicaciones.

Por la crisis económica de ambos países, y la política en Angola, el Ajuste Complementario de 1983 estableció las prioridades en las relaciones entre los países y las alternativas económicas para hacerlas viables. De tal manera que el Ajuste Complementario de 1983 delineó directrices generales para el financiamiento de las relaciones de comercio e inversión entre Angola y Brasil, con vistas a: i) en lo tocante al comercio, garantizar a Angola el abastecimiento de alimentos y otros bienes de consumo durante su periodo de reconstrucción, así como de materias primas (artículo I y Anexo); y ii) en

${ }^{24}$ En relación con esas transacciones, véase Penha, op. cit., p. 174; ejemplos de countertrade registrados en el periodo pueden encontrarase en Guerreiro, entrevista citada, p. 10.

${ }^{25}$ Acerca de la situación económica de Brasil, véase Luiz Carlos Bresser-Pereira, "State-Society Cycles and Political Pacts in a National-Dependent Society: Brazil”, Latin American Research Review, vol. 50, núm. 2, 2015, pp. 13-15.

${ }^{26}$ El marco oficial del fin de la guerra civil en 2002 se dio con la firma del Memorando de Entendimiento de Lusaka, entre el Frente Nacional para la Liberación de Angola (FNLA), el partido en el poder, y los rebeldes que representaban la UNITA. Para más información sobre estos partidos y la guerra civil, véase Adriano Souza et al., "Guerra civil e o desenvolvimento econômico em Angola", Revista de Economia (Anápolis), vol. 7, núm. 2, julio-diciembre de 2011, pp. 6 ss. 
lo que se refiere al comercio de servicios e inversiones, garantizar la provisión de servicio para el Complejo Hidroeléctrico de Capanda, ${ }^{27}$ que tenía como uno de sus operadores a Oderbrecht, empresa privada brasileña (artículo II). Todas las operaciones, según el Ajuste Complementario, eran financiadas por el Banco de Brasil S. A., empresa de economía mixta, por medio de la Cámara de Comercio Exterior (CACEX), creada en los años cincuenta, para financiar las exportaciones de Brasil. ${ }^{28}$ En el acuerdo, Brasil se comprometió a conceder un millón de dólares como crédito para operaciones de comercio e inversión con Angola (Anexo, párrafo d).

La innovación principal de este proceso de financiamiento fue que las partes en el Acuerdo, Angola y Brasil, determinaron que el petróleo angoleño fuese garantía para la operación crediticia de Brasil en Angola. El gobierno de este país se comprometía, entonces, a proveer 20000 barriles de petróleo diarios, para garantizar el préstamo (Anexo del Acuerdo Complementario, párrafo g). Se observa que, según el Ajuste Complementario de 1983, las relaciones de comercio, inversión y financiamiento estaban predefinidas y condicionadas por el abastecimiento de petróleo angoleño, lo cual, con el tiempo, se denominó "modelo angoleño", para financiar relaciones de comercio e inversión. ${ }^{29}$ En éste, el país A ofrece

27 The Washington Post, en un informe especial sobre Angola, clasificó el Proyecto Capanda como el mayor proyecto de infraestructura en la historia del país. Básicamente, el proyecto está a cargo de compañías brasileñas y rusas, y tiene un costo estimado en más de 4000 millones de dólares. Véase http://www.washingtonpost.com/wp-adv/specialsales/spotlight/angola/article21.html

${ }^{28}$ CACEX, agencia administrativa destinada a la ubicación de apoyo financiero gubernamental, fue considerada el principal órgano para la implementación de la política desarrollista de sustitución de importaciones y promoción de exportaciones puesta en práctica de los años sesenta a los noventa, cuando quedó extinta. Más datos sobre la cACEX y la política de desarrollo de Brasil en esta época pueden encontrarse en Silva, Da substituição de importação à substituição de exportação, Porto Alegre, UFRGs, 2004.

${ }^{29}$ Para los países en desarrollo que poseen recursos naturales, el modelo angoleño, o Angola model, representa la alternativa para obtener financiamiento y fraguar sus proyectos de desarrollo económico. Un análisis más detallado sobre este tipo de operación y los impactos en el desarrollo de Angola, aparece en el libro de Lucy Corkin, Uncovering African Agency: Angola's Management of China's Credit Lines, Farnham, Ashgate, 2013. La autora critica la denominación de "modelo 
recursos naturales a cambio de infraestructura aportada por el país $\mathrm{B}$, según el principio del trueque (barter system).

En la figura que sigue, intentamos esquematizar este tipo de relación económica:

\section{FigurA 1}

La coordinación público-privada para financiamiento, comercio e inversión

\begin{tabular}{llll}
\hline Nivel 1 & Gobierno brasileño & $\begin{array}{l}\text { Ajuste Complementario al } \\
\text { Acuerdo de Cooperación }\end{array}$ & Gobierno angoleño \\
\hline Nivel 2 & Exportador & Contrato comercial & Importador \\
\hline Nivel 3 & $\begin{array}{l}\text { Institución financiera } \\
\text { (banco público/ } \\
\text { Banco do Brasil) }\end{array}$ & Acuerdo sobre procedimientos & $\begin{array}{l}\text { Institución financiera } \\
\text { (banco público) }\end{array}$ \\
\hline Nivel 4 & $\begin{array}{l}\text { Compañía estatal } \\
\text { (Petrobras) }\end{array}$ & $\begin{array}{l}\text { Contrato de abastecimiento } \\
\text { (como garantía al contrato } \\
\text { comercial, en los términos del } \\
\text { acuerdo bilateral firmado por } \\
\text { ambos Estados) }\end{array}$ & $\begin{array}{l}\text { Companía estatal } \\
\text { (Sonangol) }\end{array}$ \\
\hline
\end{tabular}

Fuente: Elaborado por los autores, a partir del Ajuste Complementario al Acuerdo de Cooperación Económica, Científica y Técnica sobre Comercio (1983).

Se prevén en el Ajuste Complementario de 1983 las funciones y obligaciones de agentes diversos, públicos y privados, que no son parte del acuerdo. Es difícil identificar dónde y cuándo los intereses y formatos jurídicos públicos y privados predominan en esa coordi-

angoleño" en las circunstancias particulares de las operaciones Angola-China. Aunque Angola signifique un importante estudio de caso para el trueque de recursos naturales por infraestructura, no es la primera vez que China hace uso de este mecanismo de financiamiento ni que Angola lo recibe. Algunas semejanzas con el caso Angola-Brasil pueden verse en Corkin, Viana y Naidin, Emerging Economies and Export Promotion Mechanisms: A Study Case of Brazil's and China's Operations in Angola, BRIcs Policy Center Policy Brief, 2012. Para una visión crítica sobre la sustentabilidad de este modelo de financiamiento, véase Saggioro Garcia, Kato y Fontes, op. cit., pp. 33-34. 
nación. Por la magnitud del Complejo Hidroeléctrico de Capanda, los contratos firmados entre la Constructora Norberto Odebrecht, la Technopromexport y el gobierno de Angola también establecieron garantías en forma de petróleo. La Odebrecht lo consideró como una sugerencia innovadora del entonces director de negocios Marc Altit, ${ }^{30}$ ya que los primeros documentos de Capanda se firmaron en 1981 por inversionistas extranjeros y el gobierno de Angola.

Los trabajos para la construcción del Complejo Hidroeléctrico de Capanda comenzaron en 1984, pero la empresa se convirtió en uno de los blancos principales durante el periodo de la guerra civil, que se extendió hasta 2002. En 1992, la construcción se interrumpió y no continuó sino ocho años después. La primera parte del proyecto -dos turbinas-concluyó en 2005 y las últimas dos turbinas, se terminaron en 2007. ${ }^{31}$ A lo largo de esas tres décadas, la Odebrecht nunca dejó de invertir en Angola, con lo que se ha convertido en el mayor empleador del país. ${ }^{32}$

La dimensión del proyecto Capanda y el gran desarrollo de una compañía brasileña en la economía angolana colocaron a Angola en una posición prominente para la cooperación técnica y económica con Brasil, como se describirá adelante.

De forma general, se puede observar que los acuerdos legales creados para apoyar las relaciones entre Brasil y Angola son soluciones creativas y pragmáticas, para atender demandas específicas de dos países en desarrollo, con diferentes órdenes de condicionantes internos. En vez de reflejarse en modelos de instrumentos jurídicos tradicionales en esta área, como los acuerdos regionales de comercio y los tratados bilaterales de inversión, Brasil y Angola actúan notoriamente por acuerdos de cooperación que han sido el lenguaje de ambos socios en diferentes periodos de su interacción.

Según se verá a continuación, las políticas neoliberales en Brasil durante la década de 1990 redimensionaron su relación con Angola

${ }^{30}$ Odebrecht, "O futuro em construção: Odebrecht e Angola”, São Paulo, 2009, p. 84.

31 Ibidem., pp. 110-117.

32 IPEA y Banco Nacional, op. cit., p. 87. 
y privilegiaron sus relaciones exteriores con países del Norte, especialmente con Estados Unidos, ${ }^{33}$ lo que también fue resultado de las prioridades angoleñas en tiempos de la guerra civil.

\section{EL REDIMENSIONAMIENTO DE LAS RELAGIONES ENTRE BRASIL Y}

ANGOla DURANTE EL NEOLIBERALISMO BRASILEÑO DE LA DÉCADA DE 1990: ¿CUÁles SON LAS ALTERNATIVAS POSIBLES?

A pesar de los esfuerzos de Brasil y Angola por mantener sólida su relación de comercio, ésta se hizo mucho menos relevante al final de la "década perdida". Las limitaciones financieras, asociadas a los cambios de orientación de las políticas económica y exterior para Angola, redujeron sensiblemente el alcance de los proyectos trazados en las décadas de 1970 y $1980 .^{34}$

Debe señalarse, con todo, que las relaciones entre Brasil y Angola no cesaron, habiéndose redimensionado según las demandas internas de cada país. Desde el gobierno de Fernando Collor de Mello, Brasil se adecuó a las recomendaciones del Consenso de Washington, las cuales privilegiaban, entre otras cosas, la apertura unilateral del mercado interno y la privatización de empresas. ${ }^{35}$

Angola concentró su agenda de política exterior, para responder a las demandas internas de su guerra civil. En estas condiciones, la preocupación del país era buscar y mantener aliados regionales y extrarregionales, para aumentar sus oportunidades de éxito en el

${ }^{33}$ Kamilla Raquel Rizzi, "Relações Brasil-Angola no Pos-Guerra Fria (19902002)", Anos 90, vol. 15, núm. 27, 2008, pp. 287-324.

${ }^{34}$ Entendemos que, entre algunos de los factores internos en Brasil que redujeron la relevancia de las operaciones de financiamiento para el comercio y la inversión con Angola, se encuentran: $i$ ) el aumento de deuda exterior brasileña, que culminó en la moratoria en 1987 y que redujo las líneas de crédito a la exportación en el país; ii) las reformas neoliberales adoptadas en Brasil, que redujeron el tamaño del Estado y su capacidad financiera; iii) compromisos internacionales en este sentido, a partir de las cartas de intención con el Fondo Monetario Internacional; y $i v$ ) el intenso apoyo de la política exterior brasileña a las misiones de paz coordinadas por las Naciones Unidas (United Nations Angola Verification Mission UNAVEM) en Angola, con vistas a terminar con la guerra civil.

${ }^{35}$ Rizzi, art. cit., p. 289. 
conflicto civil. Brasil era uno de esos aliados, lo que no garantizó una balanza comercial positiva, ante una Angola de mercado reducido en razón de la crisis internacional. ${ }^{36}$

Como se observa en los relatos históricos, las relaciones bilaterales directas se mantuvieron a lo largo de la década de 1990. Al inicio de ésta, el presidente José Eduardo dos Santos visitó Brasil con ocasión de la toma de posesión de Fernando Collor de Mello, quien retribuyó la visita al año siguiente, con la cual se reforzó la tradición de cooperación y solidaridad entre estos países. En esta ocasión se firmó incluso el importante Protocolo de Intenciones en el Área de Desarrollo Educacional, para recibir estudiantes angoleños de licenciatura y posgrado en universidades brasileñas. ${ }^{37}$

Un aspecto bastante importante para mantener las relaciones bilaterales entre Brasil y Angola en este periodo se debió a la participación de actores privados, como Odebrecht, ${ }^{38}$ y a la presencia de Petrobras ${ }^{39}$ en Angola, en la década de 1970, como parte de la "política exterior del tercer mundo" del presidente Geisel. ${ }^{40} \mathrm{Un}$ indicador de la importancia de la empresa Odebrecht y de Petrobras en la agenda bilateral Brasil-Angola es la participación de representantes de estas empresas junto con funcionarios de rango elevado de los gobiernos de Brasil y Angola en la conferencia para tratar el tema "Las relaciones entre Brasil y Angola", en agosto de $1993 .{ }^{41}$

\section{${ }^{36}$ Ibid., p. 295.}

37 Ibid., p. 298.

${ }^{38}$ Odebrecht se instala en Angola por primera vez en 1984. Véase Saggioro Garcia, Kato y Fontes, op. cit., p. 11.

${ }^{39}$ Petrobras se instala en Angola al final de la década de 1970 por medio de Braspetro, su brazo internacional, pretendiendo garantizar reservas alternativas de petróleo. Como regla, Petrobras mantuvo una actuación discreta hasta 2006, periodo en que la empresa obtiene derechos de exploración en nuevos bloques. Mientras tanto, con el descubrimiento de Pre-Sal brasileño, la empresa adopta una estrategia con miras a la exploración interna de petróleo. Véase Saggioro Garcia, Kato y Fontes, op. cit., p. 22.

40 Véase Virginia Fontes y Ana Garcia, "Brazil's New Imperialism”, en Leo Panitch, Greg Albo y Vivek Chibber (orgs.), Socialist Register 2014: Registring Class, Londres, Merlin Press, 2014, pp. 300-320.

${ }^{41}$ Rizzi, art. cit., p. 300. 
La actuación exitosa de Odebrecht y Petrobras ${ }^{42}$ en la década de 1990 contrasta con el redimensionamiento de la agenda política exterior brasileña. El éxito de la actuación de Odebrecht en Angola se debió a: i) apoyo gubernamental, ii) capacidad de movilizar personas, recursos estratégicos, financieros y políticos, para alcanzar sus objetivos, iii) la buena relación entre Brasil y Angola, iv) la lengua común, v) la planeada integración y sociedad en el mercado local, vi) la inversión en la capacitación tecnológica y gerencial de los quipos, vii) la utilización de formas modernas de gestión. ${ }^{43}$ La actuación de esta empresa es tan importante para el imaginario de las relaciones Brasil-Angola, a grado tal que la hidroeléctrica de Capanda se haya tomado por la consolidación de la actuación brasileña en Angola, aunque las relaciones bilaterales en el plano estatal fuesen próximas desde $1975 .{ }^{44}$

La historia de las relaciones estatales entre Brasil y Angola muestra señales de desgaste durante la década de 1990. Un movimiento que agravó aún más esta relación bilateral fue la decisión del gobierno angoleño de suspender, en 1994, todas las garantías en petróleo. ${ }^{45}$ Angola tenía por entonces una deuda de aproximadamente 800 millones de dólares americanos con el gobierno brasileño. Esa decisión agravó el declive del comercio entre los dos países, pues en 1995 Brasil tuvo, por primera vez, un déficit de 41 millones de dólares en su balanza comercial con Angola. ${ }^{46}$ La cancelación de las garantías perjudicó incluso el relanzamiento, en

42 Hasta 1997, Petrobras alcanzó la cima de su producción en territorio angoleño con 11000 barriles de petróleo (Rizzi, art. cit., p. 303).

${ }^{43}$ Ivo de Santana, A experiência empresarial brasileira na África (de 1970 a 1990), Salvador, Ponto y Virgula Publicações, 2003, p. 182.

${ }^{44}$ Véase Saggioro Garcia, Kato y Fontes, art. cit., p. 26.

${ }^{45}$ José Flávio S. Saraiva, O lugar da África: a dimensão atlântica da política externa do Brasil, Brasilia, UnB, 1996, pp. 219-220.

${ }^{46}$ Luiz Felipe Lampreia, Documento relativo à visita de trabalho do ministro das Relações Exteriores, Luiz Felipe Lampreia, a Angola, sobre: o comércio, a dívida e a cooperação bilaterais; interesses de empresas brasileiras; a Comunidade de Países de Língua Portuguesa (CPLP) e as situações da Guiné-Bissau e da República Democrática do Congo. LFL mre2 1999.05.31. Río de Janeiro, FGV/CPDoc, 1999, p. 26, en http://docvirt.com/docreaderFGV/DocReader.aspx?bib=AC_LFL_MRE $2 \&$ PagFis $=2694 \&$ Pesq $=$ 
1995, del proyecto Capanda, al considerar la necesidad de recuperación de sus campos de trabajo y de sus activos. ${ }^{47}$ En esas circunstancias, se firmó el 15 de agosto de 1995 el Acuerdo de Renegociación de Deuda entre Angola y Brasil.

Por primera vez en esta relación bilateral, el Acuerdo de Renegociación de Deuda fue un instrumento oficial que no invocó la figura de la cooperación. Se considera, por tanto, que puede verse como un producto de las políticas económicas liberales más acentuadas y definidas por la escasez de recursos en el primer periodo de la administración de Fernando Henrique Cardoso. ${ }^{48}$ En 1995, los términos del Acuerdo de Renegociación reconocieron una deuda de Angola con Brasil de 382 millones de dólares, acumulados con 54 millones de dólares en intereses (artículo i); definieron un plazo de quince años para el pago (artículo II); determinaron la tasa de interés aplicable (artículos III, IV y vi), el ranking de deudas concurrentes en Brasil (artículo v) y una cláusula de la nación más favorecida (artículo XIV). Tales términos trajeron novedades para las negociaciones internacionales entre países deudores/acreedores.

Desde el punto de vista jurídico, las principales innovaciones de este Acuerdo de Renegociación de Deuda pueden desarrollarse de la siguiente forma: $i$ ) a pesar de haberse firmado como un acuerdo internacional, incorpora cláusulas de ley aplicable y de resolución de controversias, al igual que medidas de cumplimiento de las obligaciones, semejantes a lo que prevén contratos privados (artículo xiI y Anexo B); ii) establece una provisión de intercambio de deudas (artículo Ix, Anexo C); y iii) vincula el suplemento de petróleo al pago de la deuda, según un memorando de entendimiento adicional, firmado el mismo día por ambas partes (MOU-1995; artículo IX). ${ }^{49}$ Por tanto, el pago de las deudas a

47 Odebrecht, O futuro em construção: Odebrecht e Angola, São Paulo, 2009, pp. 109-110.

${ }^{48}$ Carlos Alfonso Iglesias Puente, A cooperação técnica horizontal brasileira como instrumento de política externa: a evolução da cooperação técnica com países em desenvolvimento - CTPD - no 1995-2005, Brasilia, FUNAG, 2010, pp. 168-170.

${ }^{49}$ Aunque este último mecanismo sea relevante para nuestro análisis, el Mou1995 no se encuentra disponible para consulta pública. Por el aumento de las transacciones económicas entre Angola y Brasil, en los últimos años el tema del acceso 
Brasil, basado en el financiamiento anticipado de comercio e inversión, quedó garantizado de nuevo con la exportación de petróleo.

\section{La Reanudación de la CoOperación Sur-Sur: nuevas HERRAMIENTAS, NUEVOS ACTORES}

El segundo mandato de la administración de Fernando Henrique Cardoso (1999-2002) relanzó, mientras tanto, la cooperación SurSur. Algunos nuevos elementos fueron agregados a la idea, lo que influyó en la reaproximación con Angola, a saber: i) la intención de reforzar principios de la cooperación Sur-Sur, tanto en la retórica y en los discursos oficiales, como explícitamente en documentos legales firmados; ii) la ampliación del número de órganos especializados del gobierno federal en estos proyectos y su gestión por parte de la Agencia Brasileña de Cooperación; iii) la ampliación de las áreas de cooperación, para combinar temas tradicionales de comercio e inversión con aspectos sociales, como salud y educación, y asistencia en la gestión pública ${ }^{50}$. La mayoría de los especialistas defiende que fue así como la agenda del Atlántico Sur habría vuelto a la agenda de la política exterior brasileña. ${ }^{51}$

público a documentos sobre esta relación ha cobrado auge en el país sudamericano. A pesar de que Brasil haya aprobado la Ley de Acceso a Información Pública (Lei n. 12.527 de 18 de noviembre de 2011), el Acuerdo de Cooperación de 1980 estableció la confidencialidad como regla orientadora del entendimiento entre las partes. El conflicto con la Ley de Acceso a Información Pública y los acuerdos con Angola han sido incluso objeto de debate en el Senado Federal. Véase http:/ / www. senado.leg.br/atividade/materia/getTexto.asp?t=157463

${ }^{50}$ Cervo y Bueno (História da política exterior do Brasil, Brasilia, IBRI/UnB, 2002, p. 529) consideran la cooperación Sur-Sur en el gobierno de Cardoso como un nuevo paradigma de política externa del "estado logístico", un estado que no se limita a ser proveedor de servicios (estado desarrollista) ni observador pasivo del mercado y de poderes hegemónicos (estado neoliberal), sino un estado que asume el planeamiento estratégico para el desarrollo y que apoya las decisiones de otros actores económicos y sociales, con quienes divide responsabilidades y poder.

${ }^{51}$ Véase Pedro da Motta Veiga, "A África na agenda econômica do Brasil: comércio, investimentos e cooperação”, Revista Brasileira de Comércio Exterior, vol. 116, 2013, pp. 4-19; Saraiva, "Um momento especial nas relações Brasil-Angola..., pp. 225-254, y "Política exterior do Governo Lula...; Ribeiro, "Relações político co- 
En lo que respecta a Angola, a partir de 2002, movimientos importantes corroboraron también la reaproximación con Brasil. La muerte de Jonas Savimbi, líder de la UNITA, en 2002, favoreció el fin de la guerra civil. Aunque las obras en Capanda hubiesen sido reiniciadas bajo la protección severa del gobierno angoleño en 2000,52 las inversiones brasileñas en este proyecto y el abastecimiento de mercancías y servicios para esta empresa se volvieron de nuevo asaz relevantes a partir de 2002 en la política exterior brasileña atinente a Angola. Más aún, la reconstrucción del Estado y el desarrollo entero del aparato estatal de Angola se transformó en un campo nuevo para la cooperación entre Brasil y Angola.

Los analistas sostienen que la elección de Lula da Silva, en 2003, intensificó la política exterior en dirección a África. ${ }^{53}$ En el primer año de la administración de Lula, Angola y Brasil firmaron catorce nuevos acuerdos, en que se acentuaban las nuevas tendencias de cooperación arriba señaladas. Y, durante la administración de Lula, por primera vez, los representantes oficiales de ambos países pudieron cumplir la meta de realizar encuentros bienales, según los

merciais Brasil-África (1985-1990)”, tesis, FFLCH/USP, 2007; Penha, op. cit.; Cabral, "Cooperação Brasil-África para o desenvolvimento: caracterização, tendências e desafios”, Textos Cindes, núm. 26, 2011. Por el contrario, algunos autores intentan delinear la continuidad de la política brasileña en relación con Angola. Por ejemplo, Wilson Mendoça Júnior (op. cit., pp. 141 y ss.) sostiene que la relación política con África ya se había restablecido en 1995, durante el primer mandato de Cardoso (1995-1998), y Visentini (A África e as potências emergentes, Porto Alegre, Leitura XXI, 2013, pp. 91-93) destaca las acciones de Itamar Franco (1992-1994) y el apoyo, de forma directa y por medio de la onU, en el proceso de paz y de reconstrucción.

${ }^{52}$ El Grupo Odebrecht, aun con la guerra civil y la suspensión del proyecto de Capanda, llegó a mantener y a diversificar sus inversiones en Angola entre los años 1980 y 1990 (Odebrecht, op.cit.). Hoy, el Grupo Odebrecht continúa invirtiendo en Angola en áreas tan diversas como construcción, minería, supermercados, centros comerciales, energía y agronegocio, y se lo ha señalado como el mayor empleador privado en Angola (IPEA y Banco Nacional, op. cit., p. 87).

${ }^{53}$ El cambio en los departamentos del Ministerio de Relaciones Exteriores para lidiar con temas relativos al continente africano es una muestra de la importancia que éste cobró en el gobierno de L. da Silva. Más allá de designar un Departamento para ocuparse de África, ligado a la Secretaría General de Asuntos Políticos, a partir de 2002 (Decreto n. 4759/2002) se abrieron nuevas divisiones para cuidar de subregiones de África (Visentini, A África e as potências emergentes, p. 94). 
términos del artículo Ix del Acuerdo de Cooperación de 1980.54 Entonces, las partes se reunieron nuevamente en 2005 y firmaron siete acuerdos, otro más en 2007 y otros nueve en 2010. Durante ese periodo, los créditos para operaciones con Angola aumentaron más de 3200 millones de dólares ${ }^{55}$ y los flujos de comercio e inversión para ese periodo tuvieron un aumento significativo en las relaciones bilaterales, de millones a miles de millones de dólares. ${ }^{56}$

Observamos aún tres novedades en la concesión de crédito y en el proceso de cooperación, especialmente a partir de 2006-2007: i) según el Protocolo de Entendimiento Angola-Brasil, del 18 de

${ }^{54}$ Una compilación de encuentros bilaterales de Angola y Brasil, de 2003 a 2010, está disponible en IPEA y Banco Mundial (op. cit., pp. 121-124). Los informes oficiales de estos encuentros pueden encontrarse en http://www.itamaraty.gov. br $/$ index.php?option $=$ com_content\&view $=$ article $\&$ id $=4817 \&$ Itemid $=478 \& c o d \_$ pais=AGO\&tipo=ficha_pais\&lang=pt-br

${ }^{55}$ Por razones de confidencialidad, la información sobre el monto a que asciende cada exportación no está disponible para el público según se establece en los términos en el Decreto no 7.724/2012. Sin embargo, ввс Brasil, con base en la Ley de Acceso a la Información, después de solicitar los detalles de todos los créditos que el BNDEs había concedido a Angola hasta 2012, averiguó que este país había recibido 3200 millones de dólares (Estado de S. Paulo, "Com BNDEs e negócios com políticos, Odebrecht ergue «império» em Angola”, 2012). Pudimos confirmar parte de ese número en las siguientes secciones, publicadas por fuentes oficiales: la concesión de 750 millones de dólares en créditos y garantías negociadas para el periodo de 2006-2008 (MRE, Repertório de política externa: posições do Brasil); una línea adicional de crédito preaprobado en mil millones de dólares, en el periodo 2008-2009 (Protocolo Bilateral 2007); y mil millones de dólares en 2011 (BNDES, Relatório Anual 2011 / Annual Report / Informe anual, 2012). Diarios y blogs brasileños también anunciaron que, en 2012, se concedieron otros dos mil millones de dólares al país africano (Francisco Goes, "Brasil quer replicar com outros países da África modelo de comércio com Angola”, 2014; Barros, "BNDEs aprova US \$ 2 bilhões para Angola e negocia US\$ 1 bilhão para Gana”, 2012). De manera complementaria, conseguimos identificar que de 1998 a 2003, el BNDEs ofreció créditos para cerrar más de 79 transacciones de exportación a Angola, con el gobierno de este país en la condición de tenedor y con 11 empresas brasileñas como beneficiarias de los créditos (y Odebrecht como responsable de $43 \%$ de los contratos). La información sobre estas operaciones está disponible en http://www. bndes.gov.br Agradecemos el apoyo de Sarah Marinho por la investigación de los datos del BNDES.

${ }^{56}$ Véase la nota 2. 
agosto de 2007, los nuevos préstamos quedarían respaldados en una combinación de garantías, que consideró el compromiso de pagos de deudas del Acuerdo de Renegociación de 1995 y el excedente de esos pagos como condición para los nuevos préstamos, ${ }^{57}$ ii) los procesos de cooperación recibieron un formato triangular, integrando países del Norte u organizaciones internacionales en proyectos de cooperación Sur-Sur; y iii) compañías privadas locales en países del Sur pasaron a integrar esos proyectos de cooperación.

A continuación presentamos una tentativa de estructuración de las nuevas operaciones de financiamiento y su coordinación con transacciones de comercio e inversión:

Esta nueva estructura de apoyo financiero para los flujos de comercio e inversión entre las partes, que combina e integra las deudas pasadas y los pagos nuevos y garantías de crédito, fue una solución para aumentar las líneas de crédito angoleñas de $750 \mathrm{mi}$ llones de dólares a 1750 millones de dólares en 2007. Y se volvió aún más relevante en 2008, luego de la crisis financiera internacional, con la aprobación de la Política de Desarrollo Productivo (PDP) brasileña. La causa fue que la PDP estableció entre sus metas el Programa de Integración con África y garantizó al BNDES cierta estructura para actuar internacionalmente, con la intención de fortalecer las relaciones comerciales y los flujos de inversión en África. ${ }^{58}$

${ }^{57}$ El Protocolo de 2007 no está en la lista de acuerdos bilaterales publicados por el Ministerio de Relaciones Exteriores (http:/ / dai-mre.serpro.gov.br), pero se publicó en el Boletim Oficial pelo Ministério das Relações Exteriores sobre la visita del presidente Luis Inácio Lula da Silva a Angola, el 17 y 18 de agosto de 2007. Véase Ministério de Relações Exteriores, Resenhas de Política Exterior do Brasil, 2013, 1o. semestre, número 112, p. 491, en http:/ /www.itamaraty.gov.br/index.php?option=com_content\&view=article\&id=10227\&Itemid=747\&lang=pt-BR

58 IPEA y Banco Mundial, op. cit., pp. 76-77. Los principales sectores beneficiados por la medida fueron aquellos que estuvieron vinculados a obras de infraestructura. Constructoras brasileñas de gran alcance, como Norberto Odebrecht SA, Andrade Gutierrez SA y Queiroz Galvão SA pasaron a operar en obras que van desde variada distribución de abastecimiento y saneamiento básico hasta la construcción de dos hidroeléctricas. En ese espectro hay un gran espacio para obras relacionadas con el transporte, como avenidas, carreteras y autopistas. Se cuentan 85 operaciones de financiamiento preembarque de 2007 a 2015 para Angola, principalmente dirigidas para las ya citadas obras de infraestructura. El volumen de in- 


\section{FIGURA 2}

Créditos y deudas en una cuenta

\begin{tabular}{|c|c|c|c|c|}
\hline \multirow{4}{*}{ 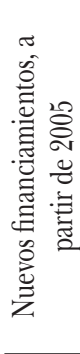 } & Nivel 1 & Gobierno brasileño & $\begin{array}{l}\text { Protocolo de } \\
\text { Entendimiento de } 2007\end{array}$ & Gobierno angolano \\
\hline & Nivel 2 & Exportador & Contrato comercial & Importador \\
\hline & Nivel 3 & $\begin{array}{l}\text { Institución financiera } \\
\text { (banco público) - BNDES }\end{array}$ & $\begin{array}{l}\text { Líneas de crédito - BNDES } \\
\text { - Exim }\end{array}$ & \multirow{2}{*}{$\begin{array}{l}\text { Institución financiera } \\
\text { (banco público - } \\
\text { Banco Nacional de } \\
\text { Angola - BNA) }\end{array}$} \\
\hline & & $\begin{array}{l}\text { Aseguradora Brasileña } \\
\text { de Crédito a la } \\
\text { Exportación - SBCE }\end{array}$ & Garantía & \\
\hline \multirow{3}{*}{ 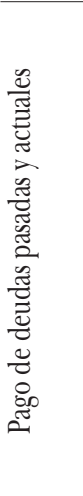 } & Nivel 1' & $\begin{array}{l}\text { Institución Financiera } \\
\text { Brasileira - ECA (Banco } \\
\text { do Brasil; BNDES) }\end{array}$ & $\begin{array}{l}\text { Memorandos de } \\
\text { entendimiento }\end{array}$ & \multirow{2}{*}{$\begin{array}{l}\text { Institución financiera } \\
\text { (banco público - } \\
\text { Banco Nacional de } \\
\text { Angola - BNA) }\end{array}$} \\
\hline & Nivel 2' & $\begin{array}{l}\text { Banco do Brasil (BB } \\
\text { Gran Cayman) }\end{array}$ & $\begin{array}{l}\text { Cuenta de garantía } \\
\text { (cobrables por las } \\
\text { exportaciones de petróleo } \\
\text { para Brasil, de acuerdo } \\
\text { con las órdenes de pago } \\
\text { definidas por el Protocolo) }\end{array}$ & \\
\hline & Nivel 3' & Petrobras & $\begin{array}{l}\text { Acuerdo de abastecimiento } \\
\text { (20 } 000 \text { barriles de } \\
\text { petróleo/día) }\end{array}$ & Sonangol \\
\hline
\end{tabular}

* El Banco Nacional de Desarrollo Económico y Social (BNDES) se fundó en 1952 para ser el instrumento principal del gobierno federal en el financiamiento de largo plazo e inversión en todos los segmentos de la economía brasileña. Véase htpp://www.bndes.gov.br

Fuente: Preparado por los autores con base en el Protocolo de Entendimiento Angola-Brasil de 2007.

versión representa una tajada significativa de la actuación del BNDEs, pues de todas las operaciones de financiamiento previas al embarque del banco entre 1998 y 2013, 9\% del monto se destinó a obras de infraestructura en Angola, que también representa el $95 \%$ del total de operaciones de la misma modalidad en el continente africano, asimismo entre 1998 y 2013. Para más información, véase http:/ / www. bndes.gov.br Algunos datos sistematizados sobre los desembolsos del periodo entre 1998 y 2013 están registrados en Sarah Marinho y Caio Borges, "O Financiamento Público e o Apoio do Governo Federal ao Comércio Exterior: em Busca da Relação entre o Bndes, o Banco do Brasil e os Investimentos do Brasil em Angola”, Relatório de pesquisa Angola e Brasil: um primeiro mapeamento regulatório de suas relações econômicas, São Paulo, FGV Direito SP, pp. 118-145 (en prensa). 
En el caso de Angola, el proyecto de la Compañía de Bioenergía de Angola, conocida como Biocom, ilustra bien estas estructuras. Biocom es una planta para la producción de caña de azúcar, bioetanol y energía eléctrica, basada en tecnología brasileña. El proyecto es resultado de una joint venture entre el grupo brasileño Odebrecht (dueño de $40 \%$ de las acciones), la compañía estatal Sonagol $(20 \%)$ y la compañía privada angoleña Demer Angola (40\%). La inversión total fue de aproximadamente 400 millones de dólares. ${ }^{59} \mathrm{El}$ BNDEs fue una de las fuentes de financiación junto con los bancos angoleños, ${ }^{60}$ pero el proyecto también se benefició de financiamientos de organizaciones internacionales para agencias brasileñas que desarrollan cooperación técnica y de una iniciativa bilateral de Brasil y Estados Unidos. ${ }^{61}$

Se esperó que Biocom produjera 32000 toneladas de azúcar en su primer año de operación, a partir de julio de 2014. En su plena capacidad, hacia 2018-2019, este número debe aumentar a 246000 toneladas y la compañía de bioenergía indica que también producirá 30 millones de litros de etanol por año. ${ }^{62} \mathrm{El}$ azúcar ha sido uno de los productos más importantes de exportación de Brasil para Angola, pero Biocom se percibe como uno de los proyectos que deben reducir el predominio de materias primas en las

${ }^{59}$ IPEA y Banco Mundial, op. cit., p. 76. Para más detalles sobre la joint venture, formada por Odebrecht y Technopromexport, paraestatal rusa, véase Odebrecht, O futuro em construção: Odebrecht e Angola, São Paulo, 2009, pp. 81-119.

${ }^{60}$ Vaisman, "Cooperação Brasil-Angola na produção de etanol", Bridges Trade BioResReview, vol. 4, núm. 1, 2010, marzo de 2010, en http://ictsd.org/i/news/ pontes /74348/\#respond; Moraes y Mattos, "Cooperação Brasil-África em biocombustíveis durante o governo Lula: uma parceria para o desenvolvimento", $R e^{-}$ vista Conjuntura Austral, vol. 3, núm. 13, 2012, p. 66.

${ }^{61}$ Para más detalles véase S. Schlesinger, Cooperação e investimentos internacionais do Brasil: a internacionalização do etanol e do biodiesel, Río de Janeiro, FASE, 2012, pp. 9-12. En este trabajo, Schlesinger hace referencia a las entidades involucradas en este financiamiento internacional, como el Ministerio de Minas y Energía, el Ministerio de Agricultura y la EMBrapa, la cual recibió fondos del Banco Interamericano de Desarrollo, del Banco Mundial y del Fondo Internacional para el Desarrollo de la Agricultura.

${ }^{62}$ Nova Cana, "Cana: Odebrecht inicia operações em Angola em julho de 2014”, Agência Estado vía Portal do Agronegócio, 2014, en http:/ /www.apla.org. $\mathrm{br} /$ cana-odebrecht-inicia-operacoes-em-angola-em-julho-de-2014 
exportaciones para Angola. ${ }^{63}$ La Agencia Brasileña de Promoción de Exportaciones e Inversiones (APEX) ha trabajado en estimaciones sobre exportaciones de maquinaria que pueden mejorar los proyectos de cooperación emprendidos por Brasil. Según la declaración pública de Carlos Mathias, director de Biocom: "Toda esta fábrica fue «importada» de Brasil. Sólo en equipamiento agrícola brasileño se invirtieron cien millones de dólares". ${ }^{64}$

Reportes en los medios sugieren que el proyecto Biocom también recibió líneas de crédito de bancos privados en Angola, como el banco Espírito Santo. Hay otras declaraciones, según las cuales bancos privados y público-privados brasileños firmaron acuerdos con bancos privados angoleños en los últimos diez años. ${ }^{65}$ Sospechamos que esos bancos pueden estar sustituyendo al Banco Nacional de Angola en la Línea 3 de la estructura de financiamiento inserta líneas arriba (Figura 2). Esas nuevas estimaciones pueden estar cambiando y volviéndose más complejas las estructuras que sostienen los proyectos de cooperación entre ambos países y la integración de sus economías.

La actuación de la empresa Odebrecht en Angola ha sido blanco de críticas por mucho tiempo. ${ }^{66}$ En septiembre de 2015, Odebrecht fue condenada por el Ministerio del Trabajo brasileño por violar derechos fundamentales de los trabajadores en el Proyecto Biocom en Angola. ${ }^{67}$ Entre las acusaciones, se encuentran éstas: soborno, especulación y tráfico internacional de personas; ${ }^{68}$

63 Véanse al respecto los comentarios oficiales del gobierno, en el Senado Federal, sobre las inversiones de Biocom en Angola y la expectativa de cambio en el perfil de la pauta de exportación brasileña mediante el traslado de productos agrícolas para maquinarias que apoyen el agronegocio, en http://www.senado. leg.br/atividade/materia/getTexto.asp?t=157463

${ }^{64}$ Nova Cana, doc. cit.

65 IPEA y Banco Mundial, op. cit., p. 81.

${ }^{66}$ Véase Saggioro Garcia, Kato y Fontes, op. cit.

${ }^{67}$ Brasil, 2 Tribunal Laboral de Araraquara, Processo N. 10230-31.2014.5.15.00 79, 2015, en http://pje.trt15.jus.br/primeirograu/Processo/ConsultaDocumento/ listView.seam?nd=15082820465134200000021626018

${ }^{68}$ Se contrataba a los obreros de diferentes estados brasileños para trabajar en la obra de Biocom en Angola. Se atraía a los trabajadores con una remuneración diferenciada y se los mantenía en situaciones precarias en lo que respecta 
condiciones de trabajo degradantes e indignas, contrarias a los derechos de los trabajadores y la supresión del derecho de movimiento de los obreros mediante la violencia. ${ }^{69}$ Esta condena fundamenta las críticas a las operaciones de grandes empresas brasileñas en África, sobre todo cuando gran parte de las iniciativas recibe financiamiento del gobierno brasileño. La falta de transparencia de estas empresas -desde su financiamiento hasta sus prácticas- parece ser uno de los grandes desafíos de las relaciones entre Brasil y Angola.

\section{Consideraciones finales}

Teniendo en cuenta que las relaciones Sur-Sur implementaron cambios significativos en la geografía internacional de comercio e inversión, este artículo analizó los principales instrumentos legales que han servido al estímulo y a la intensificación de los lazos económicos entre Angola y Brasil. Aunque las relaciones políticas y económicas entre estos dos países se remontan a los años setenta, los flujos de comercio e inversión se intensificaron significativamente sólo a partir de la primera década del siglo que corre.

Los acuerdos legales que estructuran la intensificación de esos flujos económicos difieren de los modelos de acuerdo de comercio e inversión -usualmente denominados ARC у TвI. La característica principal de los acuerdos entre Angola y Brasil ha sido fomentar iniciativas complementarias que lidian con comercio, inversión, financiamiento y cooperación técnica. Nos parece que el objetivo de tales iniciativas es hacer que la integración económica sea viable. En este sentido, observamos aquí lo que calificamos como un sistema de transmisión, en que los flujos de inversión se basan en flujos de comercio de bienes y servicios, los cuales, a su vez, dependen

a visados y a pasaportes, los cuales retenían para limitar su desplazamiento (ibid. pp. 18-20).

${ }^{69}$ Según consta en los autos del proceso, los baños para los obreros estaban sucios y anegados, los vasos sanitarios, obstruidos, sin papel higiénico y con otros problemas. Además, se alega que los comedores no presentaban las mínimas condiciones de higiene, en los que se podía encontrar moscas y ratas (ibid. p. 16). 
también del financiamiento provisto por otros flujos comerciales. Además ha sido complementado o suplementado, como parte de eso, por iniciativas de cooperación Sur-Sur. Desde 1970, cuando iniciaron las transacciones económicas entre los dos países, las operaciones entre ellos se tornaron más sofisticadas, pasando a abarcar un número mayor de actores domésticos públicos y privados, tanto de Angola como de Brasil. Aunque van en aumento, en número y en enfoques de actividad, los actores son pocos y su interconexión parece ser vital para el éxito de las relaciones económicas. Los bancos públicos de desarrollo y los bancos comerciales, las compañías públicas, las pocas compañías privadas, así como los órganos responsables de la formulación de la política exterior, estructuran sus actividades de forma complementaria y, de tal modo, requieren de estar en sintonía.

Se desprende, hasta aquí, que las relaciones económicas entre Angola y Brasil se caracterizan por una conexión íntima entre instrumentos legales de derecho público y de derecho privado, y que agentes públicos y privados se vuelven, con frecuencia, las partes de una misma transacción. Aunque esas regulaciones tengan como base los acuerdos entre gobiernos, de todas formas las mismas conjugan los acuerdos gubernamentales referidos con contratos comerciales entre exportadores e importadores, acuerdos sobre procedimientos entre instituciones públicas de financiamiento y contratos de abastecimiento de petróleo entre compañías petrolíferas estatales. Estos acuerdos posibilitan que Angola y Brasil enfrenten los problemas de falta de financiamiento para comercio e inversión con préstamos garantizados por petróleo y de falta de capacitación con proyectos de cooperación Sur-Sur.

La falta de transparencia, sobre todo en los préstamos públicos brasileños a empresas privadas para actuar en Angola, parece ser un desafío que debe enfrentarse en la agenda bilateral de ambos países. Son tan perversos sus efectos que acaban por afectar la propia acción de ciertas empresas brasileñas, que se sienten más allá del bien y el mal como para violar incluso los derechos fundamentales de sus trabajadores en Angola, como se observa en la reciente condena de Odebrecht en sede del proyecto Biocom. 
Al tomar como ejemplo el caso de Angola y Brasil, sostenemos aquí que algunas relaciones Sur-Sur pueden haberse establecido con acuerdos legales distintos de aquellos que prevalecen en las relaciones Norte-Sur, principalmente en los modelos regulatorios conocidos como los ARC y TBI. En primer lugar, el deseo de un acuerdo Sur-Sur puede haberse impulsado por la necesidad de superar las limitaciones económicas de estos socios con respecto del sistema económico internacional, como la obtención de financiamiento y capacitación. En segundo, las dimensiones híbridas público-privadas de los acuerdos también pueden estar en consonancia con las particularidades estructurales y operacionales de sus propios sistemas capitalistas y en la condición de economías en desarrollo en el sistema internacional.

Este artículo, en fin, deja abierta una serie de cuestiones. Quizá la principal, que necesita responderse por medio de investigación de campo con entrevistas en Angola, es el papel que la élite angoleña desempeña en la estructuración de los acuerdos jurídicos con Brasil y sus empresas, así como su accountability. A la luz de las relaciones entre Angola y China, Corkin argumenta que lejos de ser explorada, como muchos quieren creer, la élite política angoleña ha moldeado activamente la naturaleza de las negociaciones con China, y debe responder al pueblo de Angola por los beneficios (o por la falta) de estas transacciones. ${ }^{70}$

Traducción de Gabriel Ramos

\section{BIBLIOGRAFÍA}

Banco Central do Brasil, "Estatísticas econômicas de capitais brasileiros no exterior", 2014, en http://www4.bcb.gov.br/rex/cbe/port/cbe.asp

Barros, Guilherme, "BNDES aprova US\$ 2 bilhões para Angola e negocia US\$ 1 bilhão para Gana”, 2012, en http://guilhermebarros.istoedinh

\footnotetext{
${ }^{70}$ Corkin, Uncovering African Agency: Angola's Management of China's Credit Lines, Farnham, Ashgate, 2013, p. 5.
} 
eiro.com.br/2012/05/10/bndes-aprova-us-2-bilhoes-para-angola-enegocia-us-1-bilhao-para-gana/

BNDEs: Banco Nacional do Desenvolvimento, Relatório Anual 2011 / Annual Report / Informe anual, 2012, http://www.bndes.gov.br/SiteBNDES/ bndes/bndes_pt/Institucional/Relacao_Com_Investidores/Relatorio_Anual/RelAnual2011.html

Brasil, 2 Tribunal Laboral de Araraquara, Processo N. 10230-31.2014.5.15. 0079, 2015, en http://pje.trt15.jus.br/primeirograu/Processo/ConsultaDocumento/listView.seam?nd=150828204651342000000216 26018

Bresser-Pereira, Luiz Carlos, "State-Society Cycles and Political Pacts in a National-Dependent Society: Brazil”, Latin American Research Review, vol. 50, núm. 2, 2015, pp. 3-22.

Cabral, Lídia, "Cooperação Brasil-África para o desenvolvimento: caracterização, tendências e desafios”, Textos Cindes, núm. 26, 2011, pp. 1-39.

Cervo, Amado Luiz y Clodoaldo Bueno, História da política exterior do Brasil, Brasilia, IBRI/UnB, 2002.

Corkin, Lucy, Uncovering African Agency: Angola's Management of China's Credit Lines, Farnham, Ashgate, 2013.

— Manuela Viana y Leane Naidin, Emerging Economies and Export Promotion Mechanisms: A Study Case of Brazil's and China's Operations in Angola, BRIcs Policy Center Policy Brief, 2012.

D'Araujo, Maria Celina y Celso Castro (orgs.), "Política externa e pragmatismo responsável”, entrevista con el presidente Geisel, Río de Janeiro, CPDOC, FGV, 1994.

Estado de S. Paulo, "Com Bndes e negócios com políticos, Odebrecht ergue «império» em Angola”, 2012, en http://www.estadao.com.br/noticias/internacional,com-bndes-e-negocios-com-politicos-odebrecht -ergue-imperio-em-angola, $932219,0 . \mathrm{htm}$

Fontes, Virginia y Ana Garcia, "Brazil's New Imperialism", en Leo Panitch, Greg Albo y Vivek Chibber (orgs.), Socialist Register 2014: Registring Class, Londres, Merlin Press, 2014, pp. 300-320.

Ghai, Gharam y Cynthia Hewitt Alcantara, “The Crisis of the 1980's in Sub-Saharan Africa, Latin America and the Caribean: Economic Impact", Social Change and Political Implications: Development and Change, vol. 21, 1990, pp. 389-426.

Goes, Francisco, "Brasil quer replicar com outros países da África modelo 
de comércio com Angola”, 2014, en http:/ / www.valor.com.br/brasil/ 2640008/brasil-quer-replicar-com-outros-paises-da-africa- modelo-decomercio-com-angola

Guerreiro, Ramiro Saraiva, "Ramiro Saraiva Guerreiro (Interview, 1985)", 2010, en http://cpdoc.fgv.br/acervo/arquivospessoais

Iglesias Puente, Carlos Alfonso, A cooperação técnica horizontal brasileira como instrumento de política externa: a evolução da cooperação técnica com países em desenvolvimento - CTPD - no periodo 1995-2005, Brasilia, FUNAG, 2010.

IPEA y Banco Mundial, Ponte sobre o Atlântico - Brasil e África Subsaariana: parceria Sul-Sul para o crescimento, Brasilia, 2011.

Lampreia, Luiz Felipe, Documento relativo à visita de trabalho do ministro das Relações Exteriores, Luiz Felipe Lampreia, a Angola, sobre: o comércio, a dívida e a cooperação bilaterais; interesses de empresas brasileiras; a Comunidade de Países de Língua Portuguesa (CPLP) e as situações da Guiné-Bissau e da República Democrática do Congo. LFL mre2 1999.05.31. Río de Janeiro, FGV/CPDoc, 1999, en http:/ / docvirt.com/docreaderFGV/DocReader.aspx?bib=AC_LFL_ MRE2\&PagFis=2694\&Pesq=

- Projeto de discurso do Presidente da República, Fernando Henrique Cardoso, por ocasião do almoço que oferece ao Presidente da República de Angola, José Eduardo dos Santos. LFL pi Cardoso, F. H. 1995.08.15. Río de Janeiro, FGV/CPDOC, 1995, en http://docvirt. com/docreaderFGV/docreader.aspx?bib=ACER_LFL_PI\&pasta= LFL\%20pi\%20Cardoso,\%20F.\%20H.\%201995.08.15

Marinho, Sarah y Caio Borges, "O Financiamento Público e o Apoio do Governo Federal ao Comércio Exterior: em Busca da Relação entre o Bndes, o Banco do Brasil e os Investimentos do Brasil em Angola”, Relatório de pesquisa Angola e Brasil: um primeiro mapeamento regulatório de suas relações econômicas, São Paulo, FGv Direito SP, pp. 118-145 (en prensa).

Mendonça Júnior, Wilson, Política externa e cooperação técnica: as relações do Brasil com a África durante os anos FHC e Lula da Silva, Brasilia, D’Plácido, 2013.

Moraes, Isaias y Rodrigues Mattos, “Cooperação Brasil-África em biocombustíveis durante o governo Lula: uma parceria para o desenvolvimento”, Revista Conjuntura Austral, vol. 3, núm. 13, 2012, pp. 54-71. 
MRE: Ministério das Relações Exteriores, Repertório de política externa: posições do Brasil, Brasilia, FUNAG, 2007. -, "Angola", 2010.

, "Resenhas de política exterior do Brasil", 2013, 1 semestre, núm. 112, 2013, p. 491, en http://www.itamaraty.gov.br/index.php? option=com_content\&view=article\&id=10227\&Itemid=747\&lang= pt-BR

Nova Cana, "Cana: Odebrecht inicia operações em Angola em julho de 2014”, Agência Estado via Portal do Agronegócio, 2014, en http:// www.apla.org.br/cana-odebrecht-inicia-operacoes-em-angola-em-julho-de-2014

Odebrecht, O futuro em construção: Odebrecht e Angola, São Paulo, 2009.

Paiva, Francisco José Mattoso, Proposta de variáveis críticas para o modelo preliminar de apoio à decisão de aquisição de refinarias em novos mercados, tesis, Río de Janeiro, Pontifícia Universidade Católica do Rio de Janeiro, 2009.

Penha, Eli Alves, Relações Brasil-África e geopolítica do Atlântico Sul, Salvador, Edufba, 2011.

Quadir, Fahimul, "Rising Donors and the New Narratives of South-South Cooperation: What Prospects for Changing the Landscape of Development Assistance Programmes?", Third World Quarterly, vol. 34, núm. 2, 2013, pp. 321-338.

Ribeiro, Cláudio Oliveira, "Relações político comerciais Brasil-África (1985-1990)", tesis, FFLCH/USP, 2007.

Rizzi, Kamilla Raquel, "Relações Brasil-Angola no Pos-Guerra Fria (19902002)”, Anos 90, vol. 15, núm. 27, 2008, pp. 287-324.

Saggioro Garcia, Ana, Karina Kato y Camila Fontes, "A história contada pela caça ou pelo caçador? Perspectivas sobre o Brasil em Angola e Moçambique", Instituto PACS, 8 de marzo de 2013, en http://www. pacs.org.br/2013/03/08/pesquisa-do-pacs-sobre-a-relacao-brasil-africa-a-historia-contada-pela-caca-ou-pelo-cacador-perspectivas-sobre -o-brasil-em-angola-e-mocambique/

Santana, Ivo de, A experiência empresarial brasileira na África (de 1970 a 1990), Salvador, Ponto y Virgula Publicações, 2003.

Saraiva, José Flávio S., O lugar da África: a dimensão atlântica da política externa do Brasil, Brasilia, UnB, 1996.

-, "Um momento especial nas relações Brasil-Angola: do reconhecimento da independência aos desdobramos atuais", en José Flávio S. 
Saraiva y Selma Pantoja, Angola e Brasil nas rotas do Atlântico Sul, São Paulo, Bertrand Brasil, 1999, pp. 225-254.

, "Política exterior do Governo Lula: o desafio africano", Revista Brasileira de Política Internacional, vol. 45, núm. 2, 2002, en http:/ / www. scielo.br/scielo.php?script=sci_arttext\&pid=S0034-73292002000 200001\&lng=en\&nrm=iso

Schlesinger, Sergio, Cooperação e investimentos internacionais do Brasil: a internacionalização do etanol e do biodiesel, Río de Janeiro, FASE, 2012.

Silva, Heloísa Conceição, Da substituição de importação à substituição de exportação, Porto Alegre, Ufrgs, 2004.

Silveira, Antônio Azeredo da, entrevista de 1978, en http:/ / docvirt.com/ docreaderFGV/docreader.aspx?bib=Acervo_AAS\&pasta=AAS $\% 20$ mre\%20ag\%201977.11.25

Souza, Adriano, D. F. Garcia da Silva, M. Dillman, M. S. Guedes y S. C. Leite, "Guerra civil e o desenvolvimento econômico em Angola", $R$ evista de Economia (Anápolis), vol. 7, núm. 2, julio-diciembre de 2011, en http:/ /www.nee.ueg.br/seer/index.php/economia/article/viewFile/432/348

UnCTAD: United Nations Conference on Trade and Development, World Investment Report 2014, Ginebra, UNCTAD, 2014.

U.N. General Assembly, 29th Session, "Technical Cooperation among developing countries”, A/RES/3251(XXIX), 4 de diciembre de 1974, en http://www.un.org/en/ga/search/view_doc.asp?symbol=A/ RES/3251\%28XXIX\%29

, 67th session, "The state of South-South cooperation Report of the Secretary-General", A/67/208, 30 de julio de 2012, en http:/ www.un.org/ga/search/view_doc.asp?symbol=A\%2F67\%2F208\&Su bmit=Search\&Lang=E

-, 64th session, "Nairobi outcome document of the High-level United Nations Conference on South-South Cooperation", A/64/222, 20 de febrero de 2010, en http:/ /ssc.undp.org/content/dam/ssc/documents /Key\%20Policy\%20Documents/Nairobi\%20Outcome\%20Document.pdf

U.N. High-level Committee on South-South Cooperation, 17th Session. Framework of operational guidelines on United Nations support to South-South and triangular cooperation, SSC/17/3, 12 de abril de 
2012, en http://www.un.org/ga/search/view_doc.asp?symbol=SSC\% 2F17\%2F3\&Submit=Search\&Lang=E

Vaisman, Rafael, "Cooperação Brasil-Angola na produção de etanol", Bridges Trade BioResReview, vol. 4, núm. 1, 2010, en http://ictsd.org/i/ news/pontes /74348/\#respond

Veiga, Pedro da Motta, "A África na agenda econômica do Brasil: comércio, investimentos e cooperação", Revista Brasileira de Comércio Exterior, vol. 116, 2013, pp. 4-19.

Visentini, P. F., A África e as potências emergentes, Porto Alegre, Leitura XXI, 2013.

y A. D. Pereira, "A Política Africana do Governo Lula”, ufrgs, NERINT, 2014, en http://www.ufrgs.br/nerint/folder/artigos/artigo 40.pdf

wTo: World Trade Organization, World Trade Report 2013, wTo, 2013.

wто Press Release, "Trade to Remain Subdued in 2013 after Sluggish Growth in 2012 as European Economies Continue to Struggle", PRESS /688, 2013, en http://www.wto.org/english/news_e/pres13_e/pr68 8_e.htm 